\title{
REVIEW
}

\section{Psychosocial interventions for dementia patients in long-term care}

\author{
Myrra Vernooii-Dassen, ${ }^{1}$ Emmelyne Vasse, ${ }^{2}$ Sytse Zuidema, ${ }^{2}$ Jiska Cohen-Mansfield ${ }^{3}$ \\ and Wendy Moyle 4 \\ ${ }^{1}$ Radboud University Nijmegen Medical Centre, Kalorama Foundation, Nijmegen, The Netherlands \\ ${ }^{2}$ Radboud University Nijmegen Medical Centre, Nijmegen, The Netherlands \\ ${ }^{3}$ Herczeg Institute on Aging and Department of Health Promotion, School of Public Health, Sackler Faculty of Medicine, Tel-Aviv University, Tel-Aviv, Israel \\ and Department of Health Care Sciences, George Washington University Medical Center and School of Public Health, Washington, DC, U.S.A. \\ ${ }^{4}$ Research Centre for Clinical and Practice Innovation, Griffith University, Brisbane, Australia
}

Background: Psychosocial interventions in long-term care have the potential to improve the quality of care and quality of life of persons with dementia. Our aim is to explore the evidence and consensus on psychosocial interventions for persons with dementia in long-term care.

Methods: This study comprises an appraisal of research reviews and of European, U.S. and Canadian dementia guidelines.

Results: Twenty-eight reviews related to long-term care psychosocial interventions were selected. Behavioral management techniques (such as behavior therapy), cognitive stimulation, and physical activities (such as walking) were shown positively to affect behavior or physical condition, or to reduce depression. There are many other promising interventions, but methodological weaknesses did not allow conclusions to be drawn. The consensus presented in the guidelines emphasized the importance of care tailored to the needs and capabilities of persons with dementia and consideration of the individual's life context.

Conclusions: Long-term care offers the possibility for planned care through individualized care plans, and consideration of the needs of persons with dementia and the individual life context. While using recommendations based on evidence and consensus is important to shape future long-term care, further well-designed research is needed on psychosocial interventions in long-term care to strengthen the evidence base for such care.

Key words: psychosocial interventions, long-term care, dementia, guidelines, nursing homes, behavioral problems

\section{Introduction}

People with dementia usually live at home until a late stage in the disease. In Europe the percentage of admissions to long-term care of people with dementia varies from $15 \%$ in Italy to $38.5 \%$ in France (Vernooij-Dassen et al., 2005). However, about $70 \%$ of persons with dementia are eventually placed in long-term care facilities (de Klerk, 2001).

Admission into long-term care is a final option that is not preferred by the majority of people and its financial costs are very high in most countries. A

Correspondence should be addressed to: Prof. Dr. M.Vernooij-Dassen, Kalorama Foundation and Radboud University Nijmegen Medical Centre, P.O. Box 9101, 114 IQ healthcare, $6500 \mathrm{HB}$ Nijmegen, Geert Grooteplein 21, Nijmegen, The Netherlands. Phone: +31 24-3666265; Fax: +31 243540166. Email m.vernooij-dassen@iq.umcn.nl. Received 4 Jan 2010; revision requested 15 Feb 2010; revised version received 3 June 2010; accepted 7 June 2010. First published online 3 September 2010. long-term care facility is a place to live, but it is often difficult to feel at home. Having to start a new life at a place you have not deliberately chosen under difficult physical and social circumstances presents a major challenge to many residents.

Yet, long-term care facilities can offer services and thereby opportunities that are not available in many people's homes. Some long-term care facilities contribute to the improvement of dementia care through the development of new psychosocial interventions that try to draw on the potential of persons with dementia and compensate for disabilities. In this way, long-term care facilities are a nursery for approaches to improve the quality of care and quality of life for persons with dementia. Psychosocial interventions aim at improving quality of life and maximizing function in the context of existing deficits. Such interventions 
use a wide range of approaches including behavior-oriented, emotion-oriented, cognitionoriented, and stimulation-oriented approaches and are carried out by a wide range of health and social care practitioners. Most psychosocial interventions aim to improve cognitive skills, mood or behavior (APA Work Group on Alzheimer's Disease and Other Dementias, 2007).

In order to give the best care possible it is important to use best practices and available evidence on psychosocial interventions. In this paper we aim to explore the evidence and consensus on psychosocial interventions for long-term care (nursing and residential homes) through reviews of research and consensus statements.

\section{Methods}

In order to identify (i) psychosocial interventions that are effective and can be implemented in daily practice, (ii) promising interventions requiring further study, and (iii) interventions that have shown insufficient evidence, we undertook

- an appraisal of research reviews, and

- an exploration of European, U.S. and Canadian dementia guidelines

\section{Search strategy}

The PubMed database, which includes reviews from the Cochrane Library, was searched using the following search terms: Dementia (MESH) AND (psychosocial OR non-pharmacological OR nonpharmacological OR intervention). The period of search was 1999 to June 2009.

Papers (reviews and guidelines) included in this overview were selected using the following criteria: focus on dementia; focus on psychosocial interventions in long-term care; review or dementia guidelines; in English. The exclusion criteria were: interventions only focused at community care; and papers not published as a review in peer reviewed journal or as dementia guideline.

\section{Results}

\section{Appraisal of reviews}

The search identified 511 papers and resulted in 52 reviews with information on psychosocial interventions, of which 27 related to long-term care. Since training of long-term care staff in psychosocial interventions is essential to improve daily care, we also included the results of a recent review by Vasse et al. (2010). Thus, 28 reviews were included. Some of these reviews focused on multiple interventions, whereas others limited themselves to the efficacy of one type of intervention, such as physical activity.

\section{Most effective psychosocial interventions}

Table 1 presents the reviews of the most effective psychosocial interventions aimed at persons with dementia.

The psychosocial interventions sought to decrease behavioral symptoms and depression and to improve functioning. Behavioral symptoms of persons with dementia in long-term care were reduced by behavioral management techniques (Livingston et al., 2005), cognitive stimulation (Livingston et al., 2005) and physical interventions (Heyn et al., 2004). Depression was decreased by behavioral management techniques and cognitive stimulation (Livingston et al., 2005). Physical and cognitive function were improved by physical activities (Heyn et al., 2004).

Behavioral management techniques included reinforcement of quiet behavior and stimulation, individualized functional analysis based on patient's superstitions, individualized bathing based on the preferences of the person with dementia, habit

Table 1. Most effective psychosocial interventions for persons with dementia in long-term care

\begin{tabular}{|c|c|c|c|}
\hline AUTHORS & TYPE OF INTERVENTION & METHODS & OUTCOME \\
\hline Livingston et al., 2005 & $\begin{array}{l}\text { Behavioral management } \\
\text { techniques centred on } \\
\text { individual patients' behavior }\end{array}$ & $\begin{array}{l}\text { RCT } 4 / 19 \\
\text { NRCT } 12 / 19 \\
\text { POCS } 3 / 19 \\
\text { Number of participants (range } 1-84 \text { ) }\end{array}$ & $\begin{array}{l}\text { Reduction of depression } \\
\text { or behavioral symptoms }\end{array}$ \\
\hline Livingston et al., 2005 & Cognitive stimulation & $\begin{array}{l}\text { RCT } 5 / 6 \\
\text { NRCT } 1 / 6 \\
\text { Number of participants (range } 27-86 \text { ) }\end{array}$ & $\begin{array}{l}\text { Reduction of behavioral } \\
\text { symptoms or depression }\end{array}$ \\
\hline Heyn et al., 2004 & Physical activities & $\begin{array}{l}\text { RCT } 30 / 30 \\
\text { Number of participants (range } \\
\text { 14-248) }\end{array}$ & $\begin{array}{l}\text { Increased fitness, physical } \\
\text { function, positive } \\
\text { behavior and cognitive } \\
\text { functioning }\end{array}$ \\
\hline
\end{tabular}

$\mathrm{RCT}=$ randomized controlled trial; NRC $\mathrm{T}=$ non-randomized controlled trial; POCS $=$ patients were their own comparison subject. 
Table 2. Staff training in long-term dementia care

\begin{tabular}{|c|c|c|c|}
\hline REVIEW AUTHORS & TYPE OF TRAINING & METHODS & OUTCOME \\
\hline Levy-Storms, 2008 & $\begin{array}{l}\text { Verbal and non-verbal } \\
\text { communication } \\
\text { behaviors }\end{array}$ & $\begin{array}{l}\text { RCT } 10 / 13 \\
\text { BAS } 3 / 13 \\
\text { Number of staff participants. } \\
\text { Range: } 32-655 \\
\text { Number of residents. } \\
\text { Range: } 30-146\end{array}$ & $\begin{array}{l}\text { Improvement in } \\
\text { communication during } \\
\text { day care; improvement } \\
\text { in quality of life for } \\
\text { residents }\end{array}$ \\
\hline Vasse et al., 2010 & $\begin{array}{l}\text { Staff communication } \\
\text { techniques for use in } \\
\text { daily routine }\end{array}$ & $\begin{array}{l}\text { RCT } 2 / 9 \\
\text { NRCT } 7 / 9 \\
\text { Number of staff participants. } \\
\text { Range: } 31-124 \\
\text { Number of residents. } \\
\text { Range: } 22-194\end{array}$ & $\begin{array}{l}\text { Improvement in } \\
\text { communication; } \\
\text { improvement in quality } \\
\text { of life for residents }\end{array}$ \\
\hline Kuske et al., 2007 & $\begin{array}{r}\text { Extensive interventions } \\
\text { and ongoing support }\end{array}$ & $\begin{array}{l}\text { RCT } 6 / 21 \\
\text { NRCT } 3 / 21 \\
\text { BAS } 12 / 21 \\
\text { Number of staff participants: range 3-134 } \\
\text { Number of residents: Range } 13-105\end{array}$ & $\begin{array}{l}\text { Improvement of staff } \\
\text { resident interaction }\end{array}$ \\
\hline
\end{tabular}

$\mathrm{RCT}=$ randomized controlled trial; NRC $\mathrm{T}=$ non-randomized controlled trial; BAS = before-and-after study.

training for activities of daily living tasks (dressing) and behavior therapy emphasizing pleasant events (Livingston et al., 2005). Cognitive stimulation has been derived from reality orientation, but uses information processing rather than factual knowledge to address problems in functioning (Livingston et al., 2005). Physical exercise included walking, isotonic exercises and chair exercises (Heyn et al., 2004).

Table 1 indicates the number of studies, design and number of participants for each method. Behavioral management techniques were evaluated in 19 studies of which four used RCTs and 12 nonrandomized controlled trials. Nearly all cognitive stimulation studies and all physical activity studies were evaluated using RCTs.

The reviews did not provide specific information on settings and also included community dwelling persons with dementia. Information on MMSE scores was only given by Heyn et al. (2004). The MMSE scores were reported in 22 studies ( $75 \%$ of the investigations). The scores ranged from 6 to 25 on a scale ranging from 0 to 30 . The mean MMSE SD was 16.5-7.0 which was classified as a moderate cognitive impairment (Heyn et al., 2004).

The most successful staff training programs are presented in Table 2. Improvement of staff-resident interaction behavior was demonstrated when extensive interventions, including improvement in activities of daily living, were used (Kuske et al., 2007; Levy-Storms, 2008; Vasse et al., 2010). In addition, staff communication training positively affected residents' quality of life (Levy-Storms, 2008; Vasse et al., 2010). Levy-Storms (2008) concludes that in order to sustain improvement, nursing aides need more training in therapeutic communication and also ongoing, dedicated supervision in psychosocial aspects of care.

The methodological quality of the reviewed studies was good, with a relatively high number of RCTs or controlled studies and relatively high numbers of participants.

\section{Promising interventions requiring further study}

We defined "promising" interventions as those having a positive, albeit not always significant impact. Several interventions were considered to be promising with regard to reduction of neuropsychiatric symptoms, such as structured activities (Cohen-Mansfield, 2001), massage and touch (Viggo Hansen et al., 2006), reminiscence (Woods et al., 2005), unmet needs interventions (Ayalon et al., 2006), aromatherapy (Holt et al., 2003), and music therapy (Vink et al., 2004). In general, the most promising interventions appear to be those that are individually tailored and behaviororiented (Ayalon et al., 2006).

Some reviews focused on the type of behavior to be treated rather than on the type of intervention used. A review of interventions to reduce agitated behavior reported promising results, especially of stimulus control interventions (Spira and Edelstein, 2006). Research on the etiology of vocal disruption is still in its infancy, but positive treatment results have been found in case studies and in one RCT (von Gunten et al., 2008). Depression was reduced by multiple component interventions in $7 / 11$ studies (Teri et al., 2005). Disruptive behavior has been 
reduced in 8/14 studies using problem-solving therapies that identify and address antecedents and consequences of disruptive behavior and increase pleasant events (Logsdon et al., 2007).

\section{Interventions showing insufficient evidence}

There is insufficient evidence from several randomized trials to allow any conclusion to be drawn about the efficacy of validation therapy for people with dementia or cognitive impairment (Neal and Barton Wright, 2003) and no robust evidence exists so far to recommend the use of any non-pharmacological intervention to reduce or prevent wandering in people with dementia (Price et al., 2000; Robinson et al., 2006; 2007). However, wandering can be accommodated with proper design or potentially with use of technology. In addition, cognitive training and cognitive rehabilitation have not been found to be effective (Clare et al., 2003).

Although snoezelen was considered to be a useful treatment for neuropsychiatric symptoms (Chung et al., 2002; Livingston et al., 2005) and was considered to be promising in reducing apathy (Verkaik et al., 2005), a recent update of the Cochrane review by Chung and Lai (2008) showed no significant positive effects.

\section{Exploration of European, U.S. and Canadian dementia guidelines}

The results of RCTs and reviews have been used to develop guidelines and recommendations for long-term care. Nine European guidelines, the Canadian guidelines and the American Geriatrics Society (AGS) dementia guidelines were examined. The guidelines were gathered by the Interdem network (a Pan-European research group on INTERventions in DEMentia care) and the IPA long-term care network. These networks are essential in collating guideline information, since guidelines are usually in written in the national language and not always easily accessible. Within these guidelines we searched for recommendations for long-term care. Four European guidelines had no information on long-term care. Long-term care recommendations emphasized the importance of care tailored to the needs and capabilities of persons with dementia and consideration of the individual's life context. In order to provide tailor-made care, assessment is necessary.

\section{Assessment}

Comprehensive assessment is recommended including life history, social and family circumstances, current level of functioning, physical, psychosocial, cultural and spiritual identity, physical and mental health needs, and preferences for treatment (Canadian Coalition for Seniors' Mental Health, 2006; NICE/SCIE, 2006).

Some guidelines focus on specific issues such as individual daily exercise needs (Bartholomeyczik et al., 2006) or aim to identify which sensory stimuli a resident responds to positively during different caring activities (Netherlands Institute for Health Services Research, 2004). The U.S. guidelines provide detailed recommendations for assessment and treatment of depression and behavioral symptoms associated with dementia (AGS, 2003). The Canadian guidelines consider the need to develop mealtime care-giving activities to enhance nutrition and prevent behaviors that interfere with nutritional and social needs (Canadian Coalition for Seniors' Mental Health, 2006). These assessments are the basis or a prerequisite for treatment.

\section{Treatment}

The recommended treatment for people with dementia includes suggestions to deal with a variety of needs. A range of tailored interventions, such as reminiscence therapy (Bartholomeyczik et al., 2006; Canadian Coalition for Seniors' Mental Health, 2006; NICE/SCIE, 2006; Ypma-Bakker et al., 2008), multisensory stimulation (Netherlands Institute for Health Services Research, 2004; NICE/SCIE, 2006; Scottish Intercollegiate Guideline Network, 2006; Canadian Coalition for Seniors' Mental Health, 2006), animal-assisted therapy and exercise (Canadian Coalition for Seniors' Mental Health, 2006; NICE/SCIE, 2006) and cognitive behavioral therapy (NICE/SCIE, 2006), may be considered to be a part of treatment, especially for people with dementia who suffer from depression and/or anxiety. The active participation of their carers may be considered as part of the treatment (NICE/SCIE, 2006; Canadian Coalition for Seniors' Mental Health, 2006).

A specific recommendation has been made for dealing with crises. The suggestion is to try to find out what feelings cause the crisis and to distract the patient without correcting his/her reality. People with dementia who show challenging behavior should be treated with acceptance and respect during a psychiatric crisis (Bartholomeyczik et al., 2006).

\section{Care plans}

Guidelines highly recommend care plans that address the varying needs of people with different types of dementia. Care plans should focus on (a) disabilities, (b) use of strengths while considering deficits, for instance support for people to go at their own pace and participate in activities they enjoy 
(NICE/SCIE, 2006), and (c) the social context, for example the use of the social context of meals (Canadian Coalition for Seniors' Mental Health, 2006).

Care plans should also focus on risk management by indicating how care staff should identify, monitor and address environmental, physical health and psychosocial factors that may increase the likelihood of challenging behavior, especially violence and aggression.

Care plans should also consider environmental factors: overcrowding, lack of privacy, lack of activities, inadequate staff attention, poor communication between the person with dementia and staff, conflicts between staff and carers, and weak clinical leadership (NICE/SCIE, 2006). Important requirements for carrying out care plans are consistent and stable staffing, retaining a familiar environment by minimizing relocations (NICE/SCIE, 2006), and staff education (Canadian Coalition for Seniors' Mental Health, 2006; Vasse et al., 2008).

\section{Discussion}

The use of psychosocial interventions in long-term care has the potential to improve the quality of life of residents with dementia. Behavioral management techniques and cognitive stimulation have been proven to be effective in reducing behavioral symptoms and/or depression, and physical exercise has been found to improve physical and cognitive functioning and to stimulate positive behavior.

The positive results of psychosocial training programs for caregivers in long-term care indicate that these programs have the potential for improved quality of care and thereby for improved quality of life of persons with dementia.

Other interventions are promising, but they suffer from methodological weaknesses such as small numbers of participants. There is consensus described in several guidelines to recommend assessment of physical and psychosocial characteristics and needs for care, as well as on how to facilitate needs-tailored care. Care plans are highly recommended as a means of improving quality of care and quality of life.

These recommendations are consistent with those found in studies on home care in dementia which suggest that care should be tailor-made and intensive (Brodaty et al., 2003). These results support the unmet needs model (Cohen-Mansfield, 2001).

Some results seem to be contradictory such as the lack of positive results on cognitive rehabilitation and cognitive training (Clare et al., 2003) and the positive effects of cognitive stimulation (Livingston et al., 2005). More research is needed to study the differential impact of these comparable approaches.

Long-term care studies suffer from specific barriers such as being small scale owing to limited funds available for non-pharmacological dementia research as well as the challenges related to recruitment. The available RCTs are of relatively low quality and the variation in outcome measures makes it too early to provide any conclusive indication of the effectiveness of these psychosocial interventions. The question is also whether the RCT is the most appropriate design to measure effects of long-term care psychosocial interventions. Unlike pharmacological studies, it can be difficult or impossible for patients and treating professionals to be blinded to the treatment intervention. The nature of the disease and personal preferences should be considered when measuring effects. Some psychosocial interventions appear to have effects that are mostly small to moderate with a short duration of action. This limited action means that treatments will work best in specific, time-limited situations tailored to individual requirements (O'Connor et al., 2009a), or interventions have to be programmed into care. In the few studies that addressed within-group differences, there were marked variations in response (O'Connor et al., $2009 b$ ). Some participants benefited greatly from a treatment, while others did not (O'Connor et al., 2009b). Furthermore, long-term care studies do not cover all areas relevant for psychosocial care. More research is needed on many of the understudied psychosocial interventions such as interventions including family members and end-of-life care in long-term care settings.

The conclusions reached in this paper are constrained by the limitations of research in this field and of the use of reviews and guidelines. As a consequence, recommendations heavily depend on consensus. Limitations pertaining to the use of reviews and guidelines include the following:

(1) Because different reviews utilize different methodologies, their conclusions may vary based on the methodology rather than on the strength of evidence. For example, different reviews used different search engines: Spira and Edelstein (2006) started with only Psychinfo, and references emanating from those articles; von Gunten et al. (2008) used Pubmed, while others used multiple search engines. The populations studied varied in the different reviews; for example, some reviews also included persons who were not in long-term care. Thus, Heyn et al. (2004) reports an average MMSE score of 16.5 , which may not apply to many nursing home residents. Furthermore, different reviews used different criteria for inclusion in the review. 
Ayalon (2006), for example, included single subject design, a methodology not included in many other reviews. Some reviews included only randomized controlled studies, while others graded the quality of the studies reviewed. This can lead to differing conclusions.

(2) The terminology used to characterize interventions is inconsistent across reviews. In one review, for example, the term "behavioral interventions" included person-centered care, or supportive psychotherapy (Livingston et al., 2005). This is different from the use of this term in other papers. Furthermore, interventions often include multiple components which may be responsible for the effect, such as social contact, or positive feedback, which may be responsible for the effects in different interventions such as music therapy, exercise or validation therapy. The examination of the active ingredient in those interventions has not yet begun (Teri et al., 2005).

(3) Because of the weak quality of available studies and the stringent criteria used by reviewers, most reviews reach their conclusions on the basis of very few studies.

(4) Different interventions may be appropriate for different segments of the long-term care population. Matching is likely to be based on type of symptom, person characteristics, such as cognitive functioning, and setting. Interventions are only starting to examine such individualization (CohenMansfield et al., 2007).

(5) Reviews and guidelines have the disadvantage of missing recent developments (Chenoweth et al., 2009), so that recent significant research studies are not represented here.

\section{Conclusions}

Recommendations based on evidence and consensus are an important means of shaping future long-term care and improving the quality of life of persons with dementia in long-term care homes. Proactive individualized care plans can support this process by including recommendations for good care that meet the needs of persons with dementia. Moreover, evidence based psychosocial interventions are not automatically used and implementation strategies should be tried and evaluated in long-term care. More well-designed research is needed on psychosocial interventions in long-term care, including research on understudied issues such as the role of family members, in order to strengthen the evidence base for long-term care.

\section{Recommendations arising from this review}

- Long-term care facilities should include psychosocial interventions in care and treatment plans. (Guidelines)
- These psychosocial interventions should be tailored to the needs of the person with dementia. (Reviews)

- A toolkit of evidence based psychosocial interventions and best practices are needed to enable the best fit between needs and support. (Guidelines)

- Activities that the resident likes or used to like and cognitive stimulation should be considered. (Reviews)

- Psychosocial interventions should preferably be embedded in daily care. (Reviews)

- Education of staff should include training on the job. The training should include both coursework as well as ongoing training addressing knowledge, skills and attitude related to dementia care and training in daily care. (Reviews)

- The individual's life context including their past and their family should be known and contact with family should be facilitated. (Guidelines)

\section{Conflict of interest}

None.

\section{Description of authors' roles}

Myrra Vernooij-Dassen designed the study and wrote the paper. Emmelyne Vasse analyzed the data and assisted with writing the paper. Sytse Zuidema assisted with writing the paper. Jiska Cohen-Mansfield checked the data and edited the paper. Wendy Moyle contributed to writing the paper.

\section{Acknowledgments}

The authors wish to acknowledge the role of David Conn and John Snowdon in forming the SIG and encouraging the writing of these guidelines.

\section{References}

AGS (2003). Guidelines abstracted from the American Academy of Neurology's Dementia Guidelines for early detection, diagnosis, and management of dementia. Fournal of the American Geriatrics Society, 51, 869-873.

APA Work Group on Alzheimer's Disease and Other Dementias (2007). American Psychiatric Association Practice Guideline for the treatment of patients with Alzheimer's disease and other dementias. Second edition. American fournal of Psychiatry, 164 (Suppl.), 55-56.

Ayalon, L., Gum, A. M., Feliciano, L. and Arean, P. A. (2006). Effectiveness of nonpharmacological interventions for the management of neuropsychiatric symptoms in patients with dementia: a systematic review. Archives Internal Medicine, 166, 2182-2188.

Bartholomeyczik, S. et al. (2006). Rahmenempfehlungen zum Umgang mit herausforderndem Verhalten bei Menschen mit 
Demenz in der stationären Altenhilfe [Guidelines to support people with dementia and neuropsychiatric symptoms in institutional care]. Berlin: Bundesministerium für Gesundheit.

Brodaty, H., Green, A. and Koschera, A. (2003). Meta-analysis of psychosocial interventions for caregivers of people with dementia. Fournal of the American Geriatrics Society, 51, 657-664.

Canadian Coalition for Seniors' Mental Health (CCSMH). (2006). National Guidelines for Seniors Mental Health': The Assessment and Treatment of Mental Health Issues in Long-Term Care Home (Focus on Mood and Behavior Symptoms). Available at www.ccsmh.can.

Chenoweth, L. et al. (2009). Caring for Aged Dementia Care Resident Study (CADRES) of person-centred care, dementia-care mapping, and usual care in dementia: a cluster-randomised trial. Lancet Neurolology, 8, 317-325.

Chung, J. C. C., Lai, C. K. Y., Chung, P. M. and French, H. P. (2002). Snoezelen for dementia. Cochrane Database of Systematic Reviews, 4, CD003152.

Chung, J. C. C. and Lai, C. K. Y. (2008). Snoezelen for dementia (update). Cochrane Database of Systematic Reviews, Reviews 2002, Issue 4. Art. No.: CD003152. doi:10.1002/14651858.CD003152.

Clare, L., Woods, R. T., Moniz Cook, E. D., Orrell, M. and Spector, A. (2003). Cognitive rehabilitation and cognitive training for early-stage Alzheimer's disease and vascular dementia. Cochrane Database of Systematic Reviews, 4, CD003260.

Cohen-Mansfield, J. (2001). Nonpharmacological interventions for inappropriate behaviors in dementia: a review, summary, and critique. American fournal of Geriatric Psychiatry, 9, 361-381.

Cohen-Mansfield, J., Libin, A. and Marx, M. S. (2007). Non-pharmacological treatment of agitation: a controlled trial of systematic individualized intervention. Fournals of Gerontology: Medical Sciences, 62, 908-916.

de Klerk, M. M. Y. (2001). Report on the Elderly 2001. The Hague: Netherlands Institute for Social Research.

Heyn, P., Abreu, B. C. and Ottenbacher, K. J. (2004). The effects of exercise training on elderly persons with cognitive impairment and dementia: a meta-analysis. Archives of Physical Medicine and Rehabilitation, 85, 1694-1704.

Holt, F. E., Birks, T. P. H, Thorgrimsen, L. M., Spector, A. E., Wiles, A. and Orrell, M. (2003). Aroma therapy for dementia. Cochrane Database of Systematic Reviews 2003, 3, CD003150. (updated in 2008).

Kuske, B., Hanns, S., Luck, T., Angermeyer, M. C., Behrens, J. and Riedel-Heller, S. G. (2007). Nursing home staff training in dementia care: a systematic review of evaluated programs. International Psychogeriatrics, 19, 818-841.

Levy-Storms, L. (2008). Therapeutic communication training in long-term care institutions: recommendations for future research. Patient Education and Counseling, 73, $8-21$.

Livingston, G., Johnston, K., Katona, C. and Lyketsos, C. G. (2005). Systematic review of psychological approaches to the management of neuropsychiatric symptoms of dementia. American fournal of Psychiatry, 162, 1996-2021.
Logsdon, R.G., McCurry, S. M. and Teri, L. (2007). Evidence-based psychological treatments for disruptive behaviors in individuals with dementia. Psychology and Aging, 22, 28-36.

NICE/SCIE (2006). Dementia: Supporting People with Dementia and Their Carers in Health and Social Care. London: National Institute for Clinical Excellence and Social Care (NICE/SCIE).

Neal, M. and Barton Wright, P. (2003). Validation therapy for dementia. Cochrane Database of Systematic Reviews, 3, CD001394.

Netherlands Institute for Health Services Research (NIVEL); Verpleeghuis Waerthove (2004). Het begeleiden van mensen met dementie die apathisch zijn. Richtlijn voor verzorgenden. [Supporting Apathetic People with Dementia. Guidelines for Nursing Staff]. Utrecht: NIVEL.

O'Connor, D. W., Ames, D., Gardner, B. and King, M. (2009a). Psychosocial treatments of psychological symptoms in dementia: a systematic review of reports meeting quality standards. International Psychogeriatrics, 21, 241-251.

O'Connor, D. W., Ames, D., Gardner, B. and King, $M$. (2009b). Psychosocial treatments of behavior symptoms in dementia: a systematic review of reports meeting quality standards. International Psychogeriatrics, 21, 225-240.

Price, J. D., Hermans, D. G. and Grimley Evans, J. (2000). Subjective barriers to prevent wandering of cognitively impaired people. Cochrane Database of Systematic Reviews, 4, CD001932. Update 2009.

Robinson, L., Hutchings, D., Corner, L., Beyer, F., Dickinson, H. and Vanoli, A. (2006). A systematic literature review of the effectiveness of non-pharmacological interventions to prevent wandering in dementia and evaluation of the ethical implications and acceptability of their use. Health Technology Assessment, 10, ix-108.

Robinson, L., Hutchings, D., Dickinson, H. O., Corner, L., Beyer, F. and Finch, T. (2007). Effectiveness and acceptability of non-pharmacological interventions to reduce wandering in dementia: a systematic review. International fournal of Geriatric Psychiatry, 22, 9-22.

Scottish Intercollegiate Guideline Network (SIGN). (2006). Management of Patients with Dementia: A National Clinical Guideline. Edinburgh: Scottish Intercollegiate Guideline Network.

Spira, A. P. and Edelstein, B. A. (2006). Behavioral interventions for agitation in older adults with dementia: an evaluative review. International Psychogeriatrics, 18, 195-225.

Teri, L., McKenzie, G. and LaFazia, D. (2005). Psychosocial treatment of depression in older adults with dementia. Clinical Psychology: Science and Practice, 12, 303-316.

Vasse, E., Vernooij-Dassen, M., Cantegreil, I., Franco, M., Woods, B. and Moniz-Cook, E. D. (2008). European guidelines on psychosocial interventions. In J. Georges (ed.), Dementia in Europe Yearbook 2008: Report on European Collaboration on Dementia (pp. 88-112), Luxembourg: Alzheimer Europe.

Vasse, E., Vernooij-Dassen, M., Spijker, A., Olde-Rikkert, M. and Koopmans, R. (2010). A systematic review of communication strategies for people 
with dementia in residential and nursing homes. International Psychogeriatrics, 22, 189-200.

Verkaik, R, van Weert, J. C. and Francke, A. L. (2005). The effects of psychosocial methods on depressed, aggressive and apathetic behaviors of people with dementia: a systematic review. International fournal of Geriatric Psychiatry, 20, 301-314.

Vernooij-Dassen, M. J., Moniz-Cook, E. M., Woods, B., de Lepeleire, J., Leuschner, A. and Zanetti, O. (2005). Factors affecting timely recognition and diagnosis of dementia across Europe: from awareness to stigma. International fournal of Geriatric Psychiatry, 20, 377-386.

Viggo Hansen, N., Jørgensen, T. and Ørtenblad, L. (2006). Massage and touch for dementia. Cochrane Database of Systematic Reviews, 4, CD004989.
Vink, A. C., Birks, J. S., Bruinsma, M. S. and Scholten, R. J.(2004). Music therapy for people with dementia. Cochrane Database of Systematic Reviews, 3, CD003477. von Gunten, A., Alnawaqil, A. M., Abderhalden, C., Needham, I. and Schupbach, B. (2008). Vocally disruptive behavior in the elderly: a systematic literature review. International Psychogeriatrics, 20, 653-672.

Woods, B., Spector, A., Jones, C., Orrell, M. and Davies, S. (2005). Reminiscence therapy for dementia (Review). Cochrane Database of Systematic Reviews, 18, CD001120.

Ypma-Bakker, M. E. M. et al. (2002). Richtlijn probleemgedrag [Guideline Problematic Behavior] (updated October 2008). Utrecht: Dutch Society for Nursing Mome Physicians (NVVA). 